\section{Eine Krankengeschichte aus dem 19. Jahrhandert.} Von Dr. Johann Marcuse in Mannheim.

Anamnese: Peter de Rudder, geboren im Jahre 1823 zu Jabbeke in Westflandern, gesundes, kräftiges Individuum. Am 16. Februar 1857 erlitt er beim Fortschaffen eines gefällten Baumes eine schwere Quetschung des linken Beines mit Frakturirung der Tibia und Fibula. Trotz sofortiger ärztlicher Hülfe und Behandlung kam es zu keiner Consolidation; im Gegentheil zeigte die Bruchstelle - es handelte sich um einen complizirten Bruch - nach wenigen Wochen ein gangränöses Aussehen, perfuse Eiterabsonderung, und auch am Fussrücken des verletzten Beines bildete sich eine breite, eiternde Wunde. Im Laufe der Behandlung wurde ein ziemlich umfangreicher Sequester entfernt, sodass ein merklicher Zwischenraum zwischen den oberen und unteren Enden der Bruchstücke entstand, die nach wie vor aus der ausserordentlich übelriechenden Eiter secernirenden Wunde heraustreten. Eine vorgeschlagene Amputation wurde verweigert.

Status praesens am 2. April 1875. Patient ist in Folge des achtjährigen Krankenlagers sehr blass und abgemagert, der Kräftezustand ist stark zurückgegangen. Am oberen Drittel des linken Schienenbeines befindet sich eine hühnereigrosse offene Wunde, die eine bräunliche, sehr übelriechende Flüssigkeit absondert. Wenn der Patient mit der linken Hand das Kniegelenk stützt und mit der rechten den unteren Theil des linken Beines etwas nach rückwärts biegt, so zeigen sich die oberen und unteren Bruchenden des Waden- wie Schienbeines in der klaffenden Wunde. Der Knochen ist von Periost völlig entblösst, die Bruchstellen zeigen ein durchaus nekrotisches Aussehen. Ergreift man mit der einen Hand den oberen Theil des linken Beines; mit der anderen die Ferse, so gelingt es mit der grössten Leichtigkeit, die Ferse nach vorn zu drehen und zwar über einen Halbkreis hinaus. Wenn Patient sein Bein hin und her pendeln lässt, so erfolgt bei jeder dieser Bewegungen ein Eitererguss aus der Wunde. Auch aus der zweiten grossen Wunde am Fussrücken entleert sich übelriechender Eiter. Ein starkes Oedem ist am ganzen linken Bein vorhanden.

Diagnose: Complizirter Bruch des linken Unterschenkels, der nicht zur Heilung gelangt ist, schlotternde Pseudarthrose, Nekrose der Bruchenden, die in einer Entfernung von $3 \mathrm{~cm}$ von einander stehen, metastatische Eiterung am Fussrücken.

Therapie: Da alle angewandten Mittel vergeblich waren, eine Amputation nicht vorgenommen werden kounte in Folge der Weigerung des Patienten, ein achtjähriges Krankenlager den Patienten zu einem dekrepiden Individuum gemacht hatte, Pilgerfahrt am 7. April 1875 zur Muttergottes von Oostacker in Belgien. Der Transport kann nur mittels Krüicken und manueller Unterstïtzung mühsam bewerkstelligt werden.

Befund am 7. April 1875, unmittelbar nach erfolgtem Rundgang durch die Grotte mit Dr. med. Affenaer und Dr.med.van Hoestenberghe, vorgenommen:

Das linke Bein und derFuss, welche noch einige Augenblicke vorherstarkgeschwollengewesenwaren, hatten ihren normalen Umfang wieder angenommen, das Pflaster und die Binden, diedasBein umgaben, warenvon selbstabgefallen, die Wunden am Schienbein wie am Fussrücken warenvernarbt, die gebrochenen Knochen waren plötzlich zusammengewachsen. Es war keine Verkürzung vorhanden, die Oberfläche des Knochens an der ehemaligen Bruchstelle war völlig glatt, also war der Knochen ohne Callusbildung geheilt, Patient konnte völlig normal ohne Krücken gehen, und ohne zu hinken.

Epikrise: Patient lebte noch 23 Jahre in voller Gesundheit und Arbeitskraft und starb im Alter von 75 Jahren an einer Lungenentzündung.

Den Krankheitsverlauf wie die plötzliche Heilung bestätigen L. van Hoestenberghe, docteur en médecine, E. Royer, docteur en médecine, A. Deschamps, S. J., docteur en médecine.

Nachwort: Die Schlüsse, welche die Verfasser dieser im Jahre 1900 erstmalig erschienenen Krankengeschichte des Falles de Rudder') - also 25 Jahre nach angeblich vollzogener Heilung - aus dem Verlauf der Krankheit und der plötzlich vollzogenen Heilung ziehen, sind folgende:

Da eine plötzliche Heilung eines doppelten Beinbruchs, welcher acht Jahre bestand und unzweifelhaft nekrotische Erscheinungen an den Bruchenden aufwies, auf natürlichem Wege unmöglich ist, und dasselbe auch für die plötzliche vollkommene Veruarbung zweiter eiternder Wunden gilt - denn auch hier ist für die natïrliche Neubildung der Gewebe eine längere Zeit erforderlich --, da ferner auch

1) Guérison subite d'une fracture. Récit et étude scientifique. Braxelles 1900 . Librairie Lagaert. durch Suggestion eine plötzliche Neubildung zerstörter Gewebe nicht erfolgen kann, so ist die Heilung des complizirten Knochenbruches von de Rudder durch übernatürliche Kräfte erfolgt, welche eine offenbare Ausnahme von den Naturgesetzen bewirkt haben.

Ich glaube die Wirkung dieser ungeheuerlichen, im wissenschaftlichen Gewande einherschreitenden Darlegungen durch einen Commentar meinerseits nicht abschwächen zu sollen. 